\title{
Effect of gamma prime depletion on creep behaviour of a nickel base superalloy (Inconel alloy X-750)
}

\author{
M C PANDEY and D V V SATYANARAYANA* \\ Defence Metallurgical Research Laboratory, Kanchanbagh, Hyderabad 500058, India
}

\begin{abstract}
Specimens of a nickel base superalloy were exposed to air at $1423 \mathrm{~K}$ to study the effect of gamma prime depletion in the near-surface region on the creep behaviour of the alloy. The results showed that the gamma prime depletion in the air-exposed specimens caused a weakening effect, leading to enhanced creep rate. Kachanov's damage parameter $f$ was determined and was found to be $0-5$ indicating that the near-surface region, comprising of surface oxide, grain boundary oxide and gamma prime depleted region, carried a small fraction of the applied stress. It is further shown that the damaging effect is more pronounced in thinner specimens.
\end{abstract}

Keywords. Creep; oxidation; Inconel alloy X-750; gamma prime depletion; nickel base superalloy.

\section{Introduction}

Considerable amount of work in several nickel base superalloys have shown that prior exposure of these alloys to air leads to reduction in both rupture life and creep ductility (Chang 1972; Woodford and Bricknell 1983; Pandey et al 1992). Detailed studies on the effect of air-exposure at elevated temperatures on the creep behaviour of Inconel alloy X-750 (Pandey et al 1984, 1986, 1991, 1992; Sundararajan et al 1992; Dyson and Osgerby 1987) have shown that both air pressure and exposure temperature have significant influence. Prior exposure to air at elevated temperatures was found to cause creep weakening, resulting in enhanced creep rate and reduced rupture life. Creep embrittlement was found in cases where the alloy was exposed to air (at atmospheric pressure) below about 1373 K (Pandey et al 1991; Pandey 1996) or at reduced air pressure of about $10^{-2} \mathrm{~Pa}$ (Pandey et al 1984, 1986). Creep embrittlement was caused by diffusion of oxygen into the alloy along the grain boundaries, which led to grain boundary cavitation due to the formation of $\mathrm{CO}$ gas bubbles producing a weakening effect. The influence on creep rate due to the presence of grain boundary cavities has been modelled successfully (Pandey et al 1984). The model has been further modified to predict rupture life and creep ductility (Sundararajan et al 1992). Oxidation of elements like chromium, aluminium and titanium in the alloy matrix can also lead to the depletion of gamma prime precipitates $\left[\mathrm{Ni}_{3},(\mathrm{Al}, \mathrm{Ti})\right]$, in the near-surface region of the air-exposed alloy. It has been shown that exposure of the alloy to air at $1423 \mathrm{~K}$ for longer periods leads to increase in creep rate and reduction in rupture life without affecting creep ductility (Pandey et al 1991). This reduction in rupture life occurred due to creep weakening of the alloy, which was caused by the absence of gamma prime in the near-surface region. However, no detailed investigation has been carried out to determine the extent of damage caused by gamma prime depletion in air-exposed nickel base superalloys. In view of this, the effect of gamma prime depletion in the near-surface region on the

*Author for correspondence 
Table 1. Creep data of Inconel alloy X-750 exposed in air (specimens 1 to 5) and in vacuum (specimen 6) for $65 \mathrm{~h}$ at $1423 \mathrm{~K}$, tested at $973 \mathrm{~K}$ at a stress level of $400 \mathrm{MPa}$.

\begin{tabular}{lccccc}
\hline $\begin{array}{l}\text { Specimen } \\
\text { No. }\end{array}$ & $\begin{array}{c}\text { Diameter } \\
\text { of specimen } \\
\text { exposed } \\
(\mathrm{mm})\end{array}$ & $\begin{array}{c}\text { Gauge diameter } \\
\text { of specimen } \\
\text { tested } \\
(\mathrm{mm})\end{array}$ & $\begin{array}{c}\text { Minimum } \\
\text { creep } \\
\text { rate } \\
\left(\mathrm{h}^{-1}\right)\end{array}$ & $\begin{array}{c}\text { Time to } \\
\text { rupture } \\
(\mathrm{h})\end{array}$ & $\begin{array}{c}\text { Strain to } \\
\text { fracture } \\
(\%)\end{array}$ \\
\hline 1 & 4.62 & 4.62 & $8.3 \times 10^{-5}$ & 153 & 12.5 \\
2 & 4.67 & 4.50 & $3.20 \times 10^{-3}$ & 200 & 7.7 \\
3 & 4.68 & 4.30 & $2.3 \times 10^{-5}$ & 387 & 13.5 \\
4 & 4.65 & 4.09 & $1.5 \times 10^{-5}$ & 378 & 8.3 \\
5 & 4.70 & 3.50 & $2 \times 10^{-5}$ & 328 & 4.5 \\
6 & 9.0 & 5.0 & $1 \times 10^{-5}$ & 508 & 13.0 \\
\hline
\end{tabular}

creep behaviour of a nickel base superalloy has been studied and the findings are reported in this paper.

\section{Experimental}

The melt analysis (in wt \%) of the Inconel alloy X-750 (a trade name of the INCO family of Company) used in the present investigation is as follows (wt.\%): $\mathrm{C}, 0.03 ; \mathrm{Fe}, 7 \cdot 1 ; \mathrm{Cr}$, 15.43; Al, 0.68; Ti, 2.55; Nb, 0.94; Mn, 0.07; S, 0.001; $\mathrm{Cu}, 0.01$ and Ni, 73.12. The material was processed from the heat produced in a vacuum induction furnace. The alloy was supplied in the hot-rolled flat and hot-finished condition. Average grain size of the material was $9 \mu \mathrm{m}$. Five creep specimens of about $5 \mathrm{~mm}$ gauge diameter and $25 \mathrm{~mm}$ gauge length were exposed to air at $1423 \mathrm{~K}$ for $65 \mathrm{~h}$ and subsequently cooled in air. A double-ageing treatment was given at $1118 \mathrm{~K}$ for $24 \mathrm{~h}$, air cooled and further at $983 \mathrm{~K}$ for $20 \mathrm{~h}$ and cooled in air. Creep tests were carried out at $973 \mathrm{~K}$ at an initial stress of $400 \mathrm{MPa}$. Tested specimens were longitudinally mid-sectioned, polished and electroetched in 5\% nital solution. Microstructures were examined using optical and scanning electron microscopy.

\section{Results and discussion}

Creep data of the five specimens exposed at $1423 \mathrm{~K}$ in air (specimens 1 to 5) and that of the specimen exposed in vacuum (specimen 6) are given in table 1. Considerable creep weakening can be noted in specimen 1 (as compared with specimen 6). Machining of the outermost region by $0.085 \mathrm{~mm}$ (specimen 2 ) reduced the value of minimum creep rate by a factor of about three indicating that the outermost region was damaged considerably. Machining of the outermost region by $0.19 \mathrm{~mm}$ (specimen 3) decreased the value of minimum creep rate further. Figure 1 shows a comparison between the creep curves of specimens 1 and 3. Creep data of specimen 4 showed that removal of the outermost region up to a depth of $0.28 \mathrm{~mm}$ reduced the value of minimum creep rate slightly more as compared with specimen 3. Machining to a greater depth up to $0.6 \mathrm{~mm}$ (specimen 5) did not result in further reduction in the minimum creep rate. The minimum creep rates obtained in specimens 4 and 5 are thus almost equal to what was obtained from the 


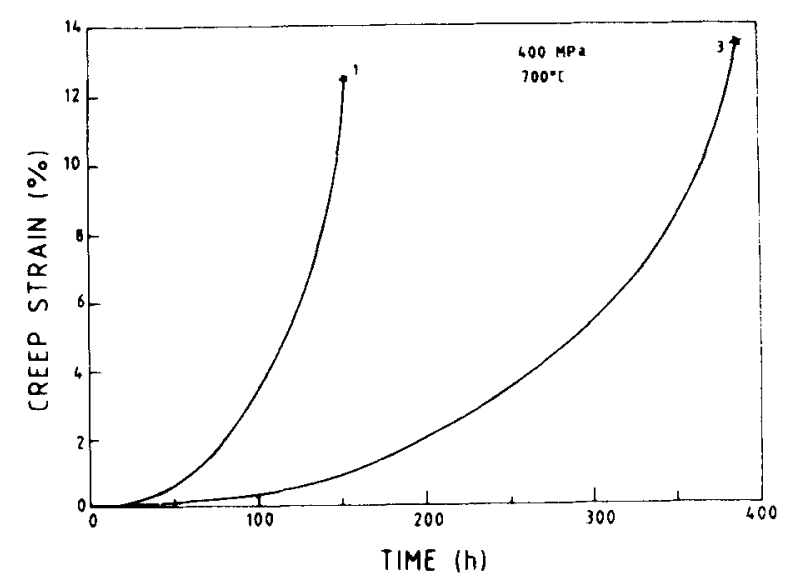

Figure 1. A comparison of the creep behaviour of specimens in air-exposed (1) and airexposed and machined (3) conditions.

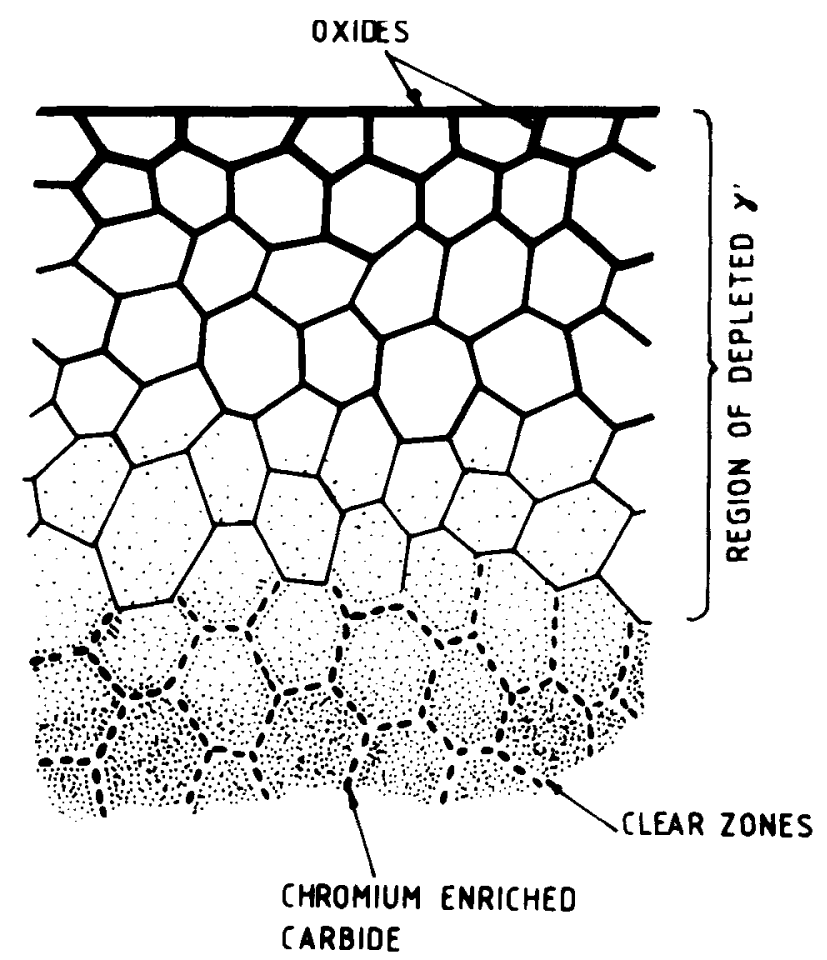

Figure 2. Schematic diagram of an air-exposed specimen showing the near surface region with little or no gamma prime precipitates.

unexposed specimen (Pandey et al 1986). Hence the minimum creep rate data show, that the depth of damage from the specimen surface was about $0.28 \mathrm{~mm}$.

Metallographic investigation of the air-exposed specimens showed that the depth of region depleted in gamma prime precipitates was about $0.30 \mathrm{~mm}$. This consisted of two regions: (i) the outermost region up to a depth of about $0.15 \mathrm{~mm}$ did not contain any gamma prime precipitates, but it was associated with oxide particles in both the matrix 


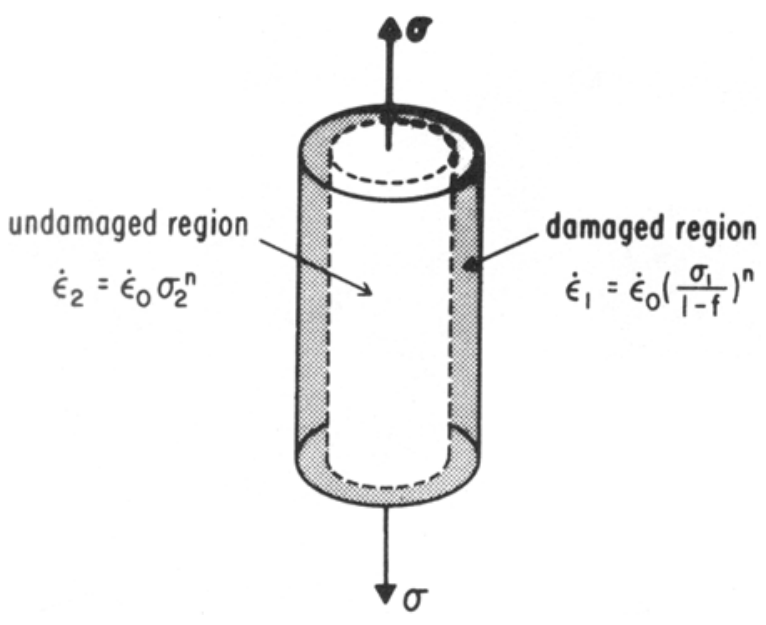

Figure 3. Schematic diagram showing damaged and undamaged regions in a cylindrical specimen.

and along the grain boundary and (ii) the remaining region contained some gamma prime precipitates (figure 2). From the creep data given in table 1 and information on the depth of gamma prime depleted region, it should be possible to determine the load carrying ability of the near-surface region of the air-exposed specimen by evaluating the Kachanov's damage parameter (Kachanov 1958).

In an earlier paper (Pandey et al 1986), the composite creep rate $\dot{\varepsilon}_{\mathrm{c}}$, of a specimen with damaged and undamaged regions (figure 3), and deforming by power law creep was given by

$$
\dot{\varepsilon}_{\mathrm{c}}=\dot{\varepsilon}_{0}\left(\frac{\sigma}{\sigma_{0}(1-f w)}\right)^{n},
$$

where $\sigma$ is the applied stress, $w$ the fractional area damaged (equal to $2 x / R(1-x / 2 R)$, where $x$ is the depth of damaged region and $R$ the radius of the specimen exposed to air), $f$ is Kachanov's damage parameter, $\dot{\varepsilon}_{0}$ and $\sigma_{0}$ are constant and $n$ the stress exponent. $n$ was found to be 14.2 in this alloy (Pandey et al 1986). Combining the creep rate equation for the undamaged (unexposed) specimen $\dot{\varepsilon}=\dot{\varepsilon}_{0}\left(\sigma / \sigma_{0}\right)^{n}$ with (1) and substituting the value of $w$, we obtain

$$
\dot{\varepsilon}_{\mathrm{c}}=\dot{\varepsilon}\left[1-\frac{2 f x}{R}\left(1-\frac{x}{2 R}\right)\right]^{-n}
$$

Using (2), the value of $f$ can be determined. When $f$ is equal to 1 , it means that the region devoid of gamma prime is completely damaged and cannot sustain any load. Substituting the data of specimens 1 and 2 from table 1 in $(2),\left(\dot{\varepsilon}_{\mathrm{c}}=8.3 \times 10^{-5} \mathrm{~h}^{-1}\right.$, $\left.\dot{\varepsilon}=3.25 \times 10^{-5} \mathrm{~h}^{-1}, x=0.085 \mathrm{~mm}, 2 R=4.67 \mathrm{~mm}\right), f$ is found to be 0.90 , which is quite close to 1 . This indicates that the outer-most region up to a depth of $0.085 \mathrm{~mm}$ comprising of oxide scale, grain boundary oxide and the matrix devoid of gamma prime precipitates sustained negligible load. Similarly, the values of $f$ for depths of $0 \cdot 19$ and $0.28 \mathrm{~mm}$ were found to be 0.56 (using data of specimens 1 and 3 ) and 0.5 (using data of 


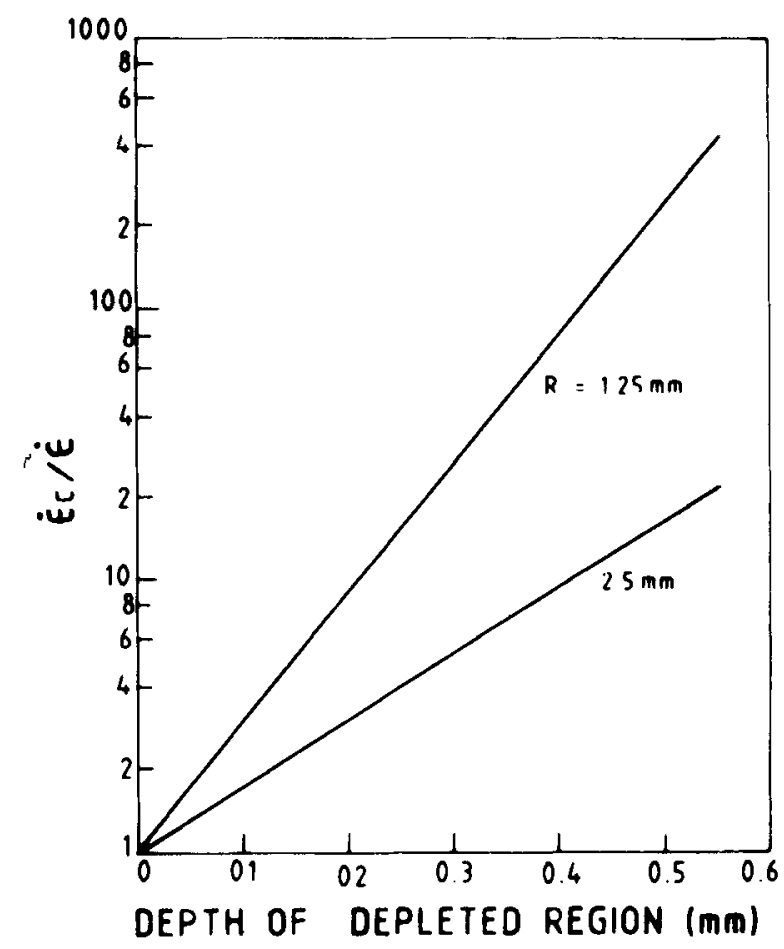

Figure 4. Variation of $\dot{\varepsilon}_{\mathrm{c}} / \mathrm{s}$ with depth of gamma prime depleted region, $(x)$, for air-exposed specimens of two section sizes.

specimens 1 and 4) respectively. It can be seen that there is almost no difference in the values of the minimum creep rate of specimens 4 and 5. This shows that the near-surface region up to a depth of about $0.28 \mathrm{~mm}$ with little or no gamma prime precipitates carried only a small fraction of the applied stress. Substituting the value of $f=0 \cdot 5,(2)$ can be generalized as

$$
\dot{\varepsilon}_{\mathrm{c}}=\dot{\varepsilon}\left[1-\frac{x}{R}\left(1-\frac{x}{2 R}\right)\right]^{-n}
$$

Using (3), values of $\dot{\varepsilon}_{\mathrm{c}} / \dot{\varepsilon}$ were calculated for different values of the depth of gamma prime depleted region $(x)$ and for two specimen diameters of 2.5 and $5 \mathrm{~mm}$ (figure 4 ). It can be noted that $\dot{\varepsilon}_{\mathrm{c}} / \dot{\varepsilon}$ is higher in the specimen with $2.5 \mathrm{~mm}$ diameter, indicating that for any depth of gamma prime depleted region, creep weakening effect is more pronounced in specimens with smaller section size. This is because, for any depth of $\gamma^{\prime}$ depletion, the fraction of $\gamma^{\prime}$ depleted area is more in smaller specimens.

Table 1 also shows that out of the five specimens exposed to air, creep ductility of two specimens ( 1 and 3 ) is about the same as that for the vacuum exposed specimen, whereas in the remaining three specimens, creep ductility is as low as $4.5 \%$. Metallographic investigation revealed the presence of abnormally coarse grains near the fracture end of the three specimens. Also, fracture was found to occur along the twin boundary in the coarse grain (figures $4 a$ and b). It appears that the twin boundaries were favourably 

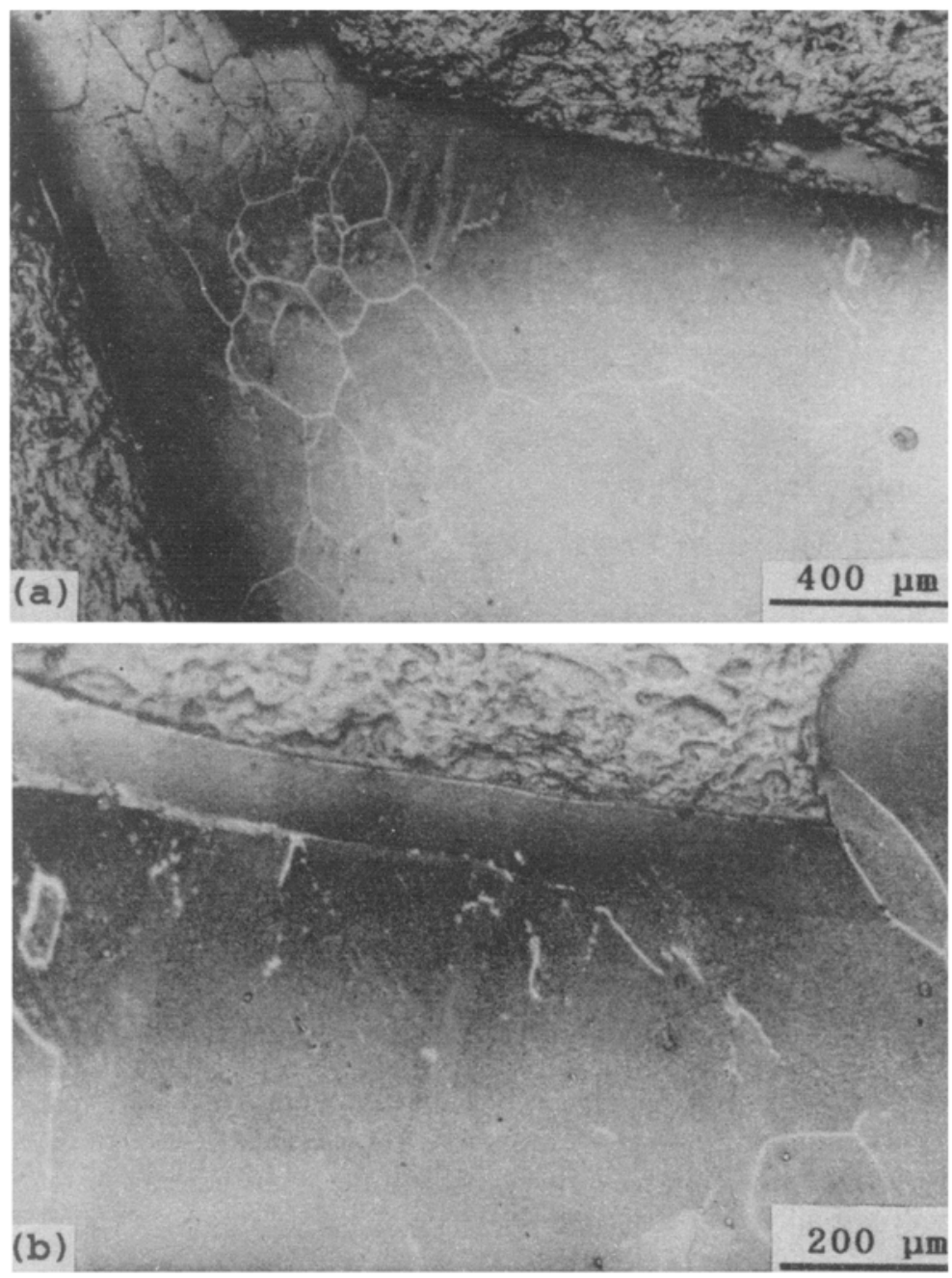

Figure 5. (a) Abnormally coarse grain structure near fracture end and (b) fracture path along twin boundary in specimen 5 .

oriented in the three specimens so that they became easy paths for crack propagation during creep (Pandey et al 1984) resulting in premature failure and poor ductility.

\section{Conclusions}

Prior air exposure of Inconel alloy X-750 specimens at $1423 \mathrm{~K}$ led to depletion of gamma prime precipitates in the near-surface region which caused considerable creep weakening. Kachanov's damage parameter, $f$, was evaluated to determine the load bearing ability of the $\gamma^{\prime}$ depleted region and has been found to have a value of 0.5 . It is shown that for any depth of gamma prime depletion, creep weakening effect is more pronounced in specimens with smaller sections. 


\section{References}

Chang W H 1972 Superalloys Processiny Sect. V AMIE MCIC-72-10

Dyson B F and Osgerby S 1987 Mater. Sci.\& Tech. 3545

Kachanov L M 1958 IZV Akad. Nauk SSSR 826

Pandey M C. Sharma K K and Satyanarayana D V V 1992 Mater. at High Temp. 10261

Pandey M C, Dyson B F and Taplin D M R 1984 Proc. R. Soc. London A393 117

Pandey M C, Taplin D M R, Ashby M F and Dyson B F 1986 Acta Metall. 342025

Pandey M C, Satyanarayana D V V and Rama Rao P 1991 Mater. at High Temp. 9167

Pandey M C 1996 Trans. Indian Inst. Metals. Special Volume (in press)

Pandey M C and Taplin D M R 1984 Proc of the sixth international conference on fracture (eds) S R Valluri, D M R Taplin. P Rama Rao, J F Knott and R Dubey (Oxford UK: Permagon Press) p. 2287

Sundararajan G, Pandey M C and Rama Rao P 1992 Mater. at High Temp. 10227

Woodford D A and Bricknell R H 1983.3 Treatize on mater. sci. and tech. (eds) C L Briant and S K Banerjee 25 D. 157 